\title{
Ethics for Records and Information Management. By Norman A. Mooradian. Chicago:
} ALA Neal-Schuman, 2018. 224 pp. Appendix, Index. Softcover. \$75.00.

\section{Norman Mooradian's Ethics for Records and Information Management provides an} overview of ethics for records and information management professionals working in a rapidly changing field. Mooradian has experience in enterprise content management as an information technology professional, holds a master's degree and PhD in philosophy from The Ohio State University, and has taught courses and published on the subject of ethics in both business and information technology. In addition to being an author and educator, he is currently the senior solutions analyst for Konica Minolta's enterprise content management division. He builds the book around defining principles and concerns related to ethical behavior that he illustrates in both hypothetical and recent historical examples of cases involving ethical dilemmas. The numerous examples are often carefully linked together and reflect on earlier principles and ideas to give a grounded guide to the foundations and application of ethical behavior in records and information management.

\section{Ethics for Records and Information Management is a very thorough text. Mooradian's} stated objective is to provide "an information professional [with a] framework that can be used to further investigate ethical issues" (p. xxv). He does this by laying the groundwork in the first two chapters and then moving on to progressively more specific concepts within professional and management ethics. Mooradian begins with an overview of the very basics of ethics to ensure that readers have a foundational understanding of ethics in general before moving on to more complex concepts relating to organizations and professions. In the first chapter, he discusses at length the "framework of ethical inquiry and decision-making" (p. 2). The author starts with broad topics like the principle of beneficence, which "enjoins us to act in such a way as to mitigate or reduce the evil (both moral and nonmoral) in the world and to act to bring about good" (p. 8) and then moves toward more abstract concepts like perfect and imperfect duties. To illustrate the abstract nature of this latter example, Mooradian defines perfect or negative duties as "duties to refrain from committing a certain action or type of action" (p. 13). Such actions include killing, stealing, or spreading propaganda, where inactivity keeps the individual from committing a moral wrong. Imperfect or positive duties are just the opposite in that they "require that you perform the type of action in question" (p. 13). An example of such an action might be donating to charity, educating yourself, or advising someone on a personal matter. Essentially, these duties require an individual to act to complete them; however, they have no end. For example, in the case of charity, no specific amount or frequency exists with which one is required to contribute to complete this duty. Similarly, one does not have a moral obligation to learn 10 languages, but learning one with the intention of communicating and understanding a culture outside your own may be sufficient. The uncertain nature of these actions makes them "imperfect" duties. Mooradian understands that these concepts are not necessarily intuitive and thus returns to them frequently throughout the text. He also realizes that important distinctions give readers context to understand the ethics of both action and inaction, as well as how philosophers have viewed the ethical nature of these types of behaviors. Hopefully, records managers are not contemplating murder, but they should 
contemplate the act of providing access or not providing access to sensitive materials and how it contributes to their ethical behavior as professionals.

The author does a good job highlighting the broader topics within the text despite the complex and theoretical nature of its subject matter. For example, as Mooradian explains in the case of ethics within a profession: "managing information is not one of the core competencies of medical professionals, so they need RIM practitioners to address their . . . needs" (p. xvii). Similarly, when discussing the sources of ethical responsibility for records professionals, he states that the "records professional gains his or her ethical responsibility from these three areas: (a) ethics in general, (b) professional ethics, and (c) organizational ethics" (p. 1). Subsequent chapters address more specific topics that RIM professionals may be likely to encounter in some form throughout their careers, like information privacy and whistle-blowing.

Headings separate most of the concepts discussed throughout the book, making it work well as a quick reference guide for ethical issues in records and information management. Mooradian is also very careful to consistently use the vocabulary that he began building in earlier chapters to reinforce the concepts that he introduces later in the book. For example, when discussing the justification for whistle-blowing within an organization, Mooradian writes: "In order to understand why this argument provides a justification, we can refer back to one of the fundamental principles ... the principle of beneficence" (p. 101). He then goes on to explain that this principle would require a potential whistle-blower to act to mitigate evil and bring about good. The text is rife with these foundational callbacks, which help readers to learn concepts as they are reinforced in each successive chapter.

Sections in subsequent chapters of the book define and discuss at length the implications of concepts such as conflicts of interest, confidentiality, copyright, trade secrets, whistle-blowing, and information privacy within our digital world. The author addresses these topics by referring to a wide range of recent, or semirecent, cases studies. For example, in his section on conflicts of interest, Mooradian discusses the role of the accounting firm Arthur Anderson in the Enron scandal. Similarly, in a section on whistle-blowers and information leaks, he references the Edward Snowden case, the National Security Administration's bulk metadata collection program, the Chelsea Manning leaks, and Julian Assange, all of which persist in the public's recent memory. Mooradian uses the Manning leaks, the Snowden case, and Wikileaks to illustrate the difference between whistle-blowing, which "has as its objective the bringing to light of a particular wrongful act" (p. 108), and leaking, which "is often done to simply bring to light information that is not available to the public" (p. 108). He also uses these cases to look at the justifications for leaking, which are often less discriminating in the release of information. To illustrate that some leaking behavior is not necessarily ethically justifiable, Mooradian points out that in cases such as Wikileaks and the Manning leaks, while photos of abused Iraqi prisoners were released to decry the conduct of the war, the released information also included "leaked Foreign Service communiques that amounted to nothing more than internal griping or gossip" (p. 111). Mooradian is careful not to define leaking as inherently bad or unethical but highlights the benefits 
of leaking in contrast to whistle-blowing, which "comes at an enormous cost to the whistle-blower and his or her family" (p. 110). He also acknowledges the ethical pitfalls of leaking, where anonymity "makes it easier for the motivation to be abusive" (p. 109). It is worth noting that although this book references some very recent examples, it does not include the Facebook-Cambridge Analytica data scandal. The issues associated with a third party collecting personal data from social media quizzes for the purpose of political advertising seem very appropriate to address in a book on ethics in records and information management. The scandal's absence is most likely because it was revealed in March 2018, just prior to the book's publication. Perhaps future editions of this text will include a section on the scandal.

Ethics for Records and Information Management would function very well as a textbook for a records and information management course. The text, though well written and concise, is dense and chock-full of concepts and examples intended to reinforce those concepts. The volume of information present in this book could be overwhelming to either new RIM professionals or to those lacking a background in ethics or philosophy; thus, it is probably best read in small doses and then discussed. This approach would allow students to better absorb the details of the principles and examples set forth in the book. Ethics for Records and Information Management could also benefit new records and information managers (RIM professionals) starting out in their careers, as Mooradian often uses examples of situations that new RIM professionals might encounter in their positions.

Andrew Johnston Harris Digital Initiatives Librarian Wright State University 